\title{
Bilateral split hand/foot malformation and $\operatorname{inv}(7)(\mathrm{p} 22 \mathrm{q} 21.3)$
}

\author{
J M Cobben, J B G M Verheij, W H Eisma, P H Robinson, R P Zwierstra, B Leegte, \\ $\mathrm{S}$ Castedo
}

\begin{abstract}
A boy with typical tetramelic split hands and feet is described. In addition, there was a large arteriovenous malformation of the right arm. Chromosome studies showed a pericentric inversion of chromosome 7: 46,XY,inv(7)(p22q21.3). Inspection of the extremities and chromosome studies in the parents were normal.

This case confirms the suggested localisation of a locus, important for early limb differentiation, on the long arm of chromosome 7 , most probably in the chromosomal region 7q21.2-7q21.3. Previously reported cases are reviewed briefly.
\end{abstract}

( $(\mathcal{H}$ Med Genet 1995;32:375-378)

Division of Plastic and Reconstructive

Surgery, Department of Surgery, University Hospital and Faculty of Medicine, Groningen, The

Netherlands

P H Robinson

Division of Paediatric Surgery, Department of Surgery, University Hospital and Faculty of Medicine, Groningen, The Netherlands

R P Zwierstra

Department of Medical Genetics, University Hospital and Faculty of Medicine, Antonius Deusinglaan 4, 9713 Aw Groningen, The Netherlands

J M Cobben

J B G M Verheij

$B$ Leegte

$S$ Castedo

University Hospital and Faculty of Medicine, Groningen, The Netherlands W H Eisma

Correspondence to: Dr Cobben.

Received 8 June 1994 Revised version accepted for publication 13 January 1995

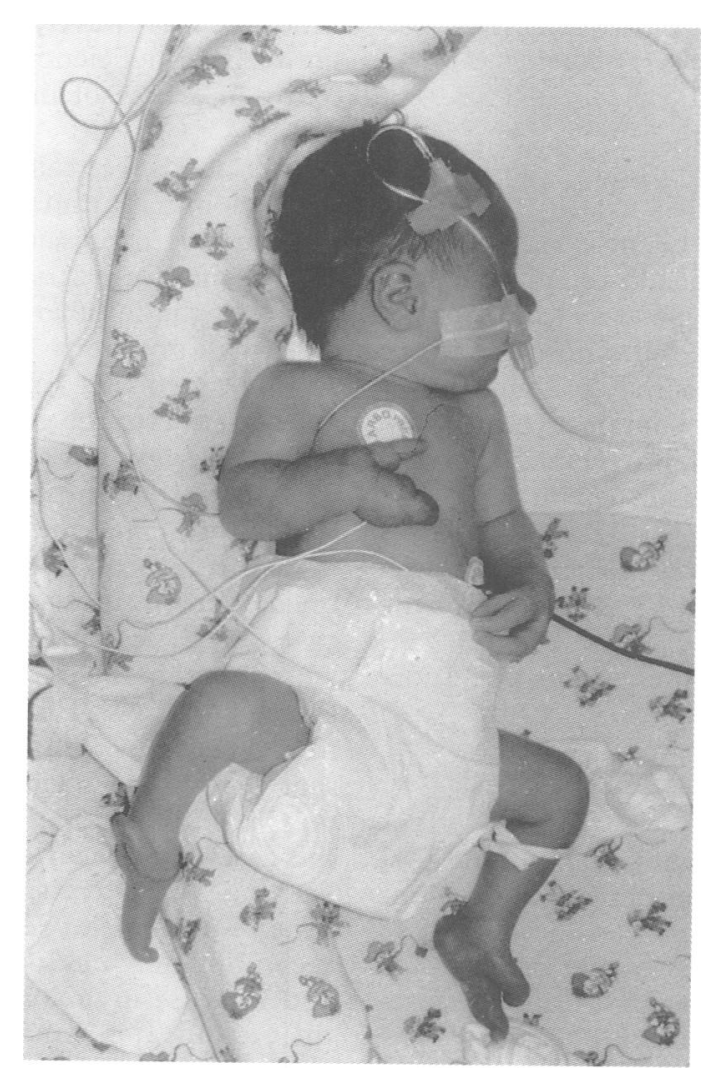

Figure 1 Case 1 at the age of 1 day. Central reduction defects of all four limbs are visible, as is the haemangiomatous malformation of the right lower arm and hand.
To date 12 cases of split hand/foot anomalies and a chromosomal rearrangement involving $7 q 21-7 q 22$ have been reported. ${ }^{1-12}$ We report the 13th case, who also had haemangioma of a limb, not described before in this chromosomal syndrome.

\section{Case report}

The proband is a boy born after an uneventful pregnancy. $\mathrm{He}$ is the first child of healthy, unrelated parents. The family history did not include any congenital malformations. Immediately after birth congenital anomalies of the hands and feet were noted, and he was referred to our hospital. Physical examination at the age of 2 days showed typical central reduction defects (split hands and feet) of all four extremities (fig 1). On the left hand the third finger was missing and on the right hand two rays were present; the most ulnar ray was swollen and red-blue coloured. On the left foot only the first and fifth toes were present, with a deep cleft in between. The right foot also showed absence of the second, third, and fourth toes and a deformity of the first toe, which was in a retroflexed position. A soft precordial systolic murmur was noted. Further examination showed no other abnormalities. $X$ ray studies of the hands and feet confirmed the split hand and foot malformation (fig 2). Arteriographic studies of the right arm showed an arteriovenous malformation on the ulnar side (fig 3). The subclavian artery was large, the radial artery was slightly hypoplastic, and the ulnar and interosseal arteries were clearly enlarged and drained into an arteriovenous conglomeration with two large veins attached to it. At the age of 2 years the boy seems mentally normal and the arteriovenous malformation, visible on the outside of the right hand, seems to have involuted somewhat. The patient is able to use both hands and can grip several objects. Simple orthopaedic footwear facilitates normal gait in this boy, who will attend playschool in due course.

Physical examination of the hands and feet of the parents was normal.

\section{CYTOGENETIC STUDIES}

Chromosomes of the patient were examined in lymphocytes from peripheral blood using 

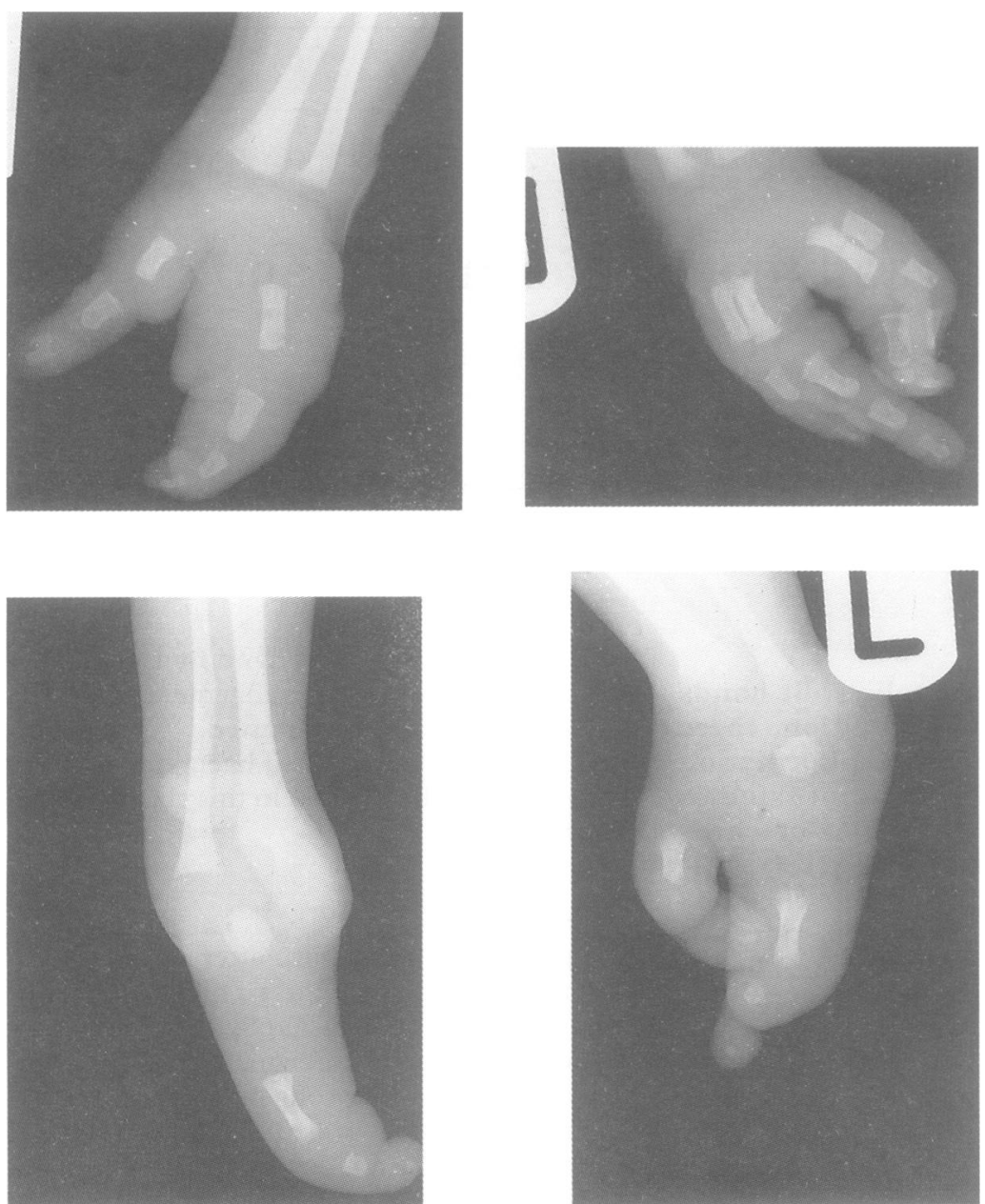

Figure $2 X$ rays of all four extremities taken at the age of one day, showing typical central reduction defects (split hands/feet). Above left is the right hand with absence of the second, third, and fourth rays and a bifid distal thumb phalanx. Above right is the left hand showing absence of the third ray. Below left is the right foot with only two rays present (the lateral one tilted upwards). Below right is the left foot with apparent absence of the second, third, and fourth rays. routine procedures and Giemsa staining. An apparently balanced inversion of chromosome 7 was found. The karyotype was: $46, \mathrm{XY}$,inv(7) (p22q21.3) (fig 4). The chromosomes were painted with a chromosome 7 library. The rearranged chromosome contained only chromosome 7 material and no segment of that chromosome was found elsewhere in the karyotype (results not shown).

A fibroblast culture from a skin biopsy was established and stored and is available for interested researchers.

The chromosomes of the parents were normal.

\section{Discussion}

Including this case, 13 cases of split hand/foot anomaly and chromosomal aberrations involving $7 \mathrm{q} 21-22$ have been described so far. $^{1-12}$ In addition there is one report of a combination of split hand/foot and a chromosomal aberration involving $7 \mathrm{q} 11 .{ }^{13}$ The cytogenetic data of these published cases and of our case are summarised in fig 5. Two reports concern split hands/feet as part of an EEC syndrome. ${ }^{613}$

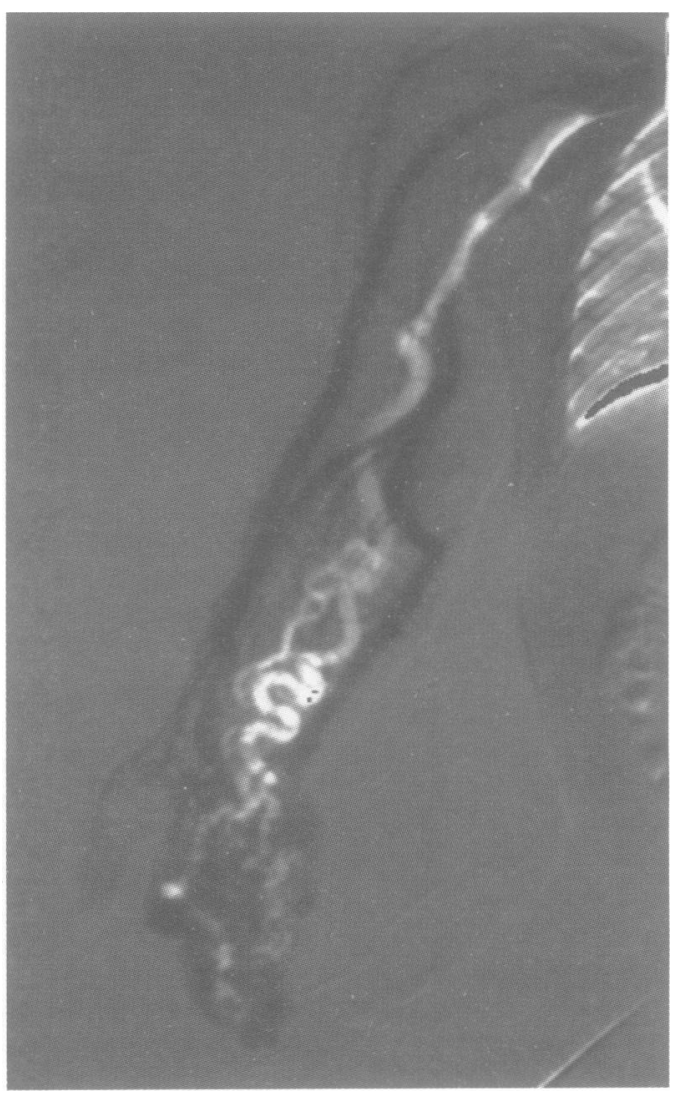

Figure 3 Angiography of the right arm showing a convoluted arteriovenous malformation in the right lower arm and part of the remaining hand.

The haemangiomatous malformation described in our case has to our knowledge not been described before in association with split hands/feet. However, a haemangioma at the site of limb deficiency has been described recently in a case of unilateral transversal limb defect. ${ }^{14}$

Split hands/feet can be inherited as an autosomal dominant trait with reduced penetrance and variable expression. ${ }^{15}$ Although the locus of the gene for ectrodactyly has not yet been assigned, the number of reports of split hand/ foot malformations with chromosomal aberrations involving $7 \mathrm{q} 21-22^{1-12}$ strongly suggest a localisation of the gene(s) responsible in that region. Cases of $7 q-$ aberrations and split hand/ foot malformation published so far are graphically represented in fig 5 .

As can be seen in fig 5, the only discrepant breakpoint on chromosome 7 in these published cases was described by Hasegawa et $a l l^{13}$ who found a balanced $t(7 ; 9)(q 11.2 ; p 12)$ in three people with EEC syndrome belonging to the same family. This has led to the suggestion that the critical region for EEC syndrome is on $7 \mathrm{q} 11.2-7 \mathrm{q} 21.3 .{ }^{16}$ We think, however, that the case of Hasegawa et $a l^{13}$ might still be in keeping with a hypothetical localisation of the gene responsible to $7 q 21-22$, admitting that no recombination has occurred between $7 \mathrm{q} 11.2$ and $7 q 21-22$ in the two informative meioses of their family. It is conceivable that the structural abnormality of chromosome 7 entailed a reduced recombination in $7 \mathrm{q}$, similar to that recently shown for chromosome 21 , when involved in a Robertsonian translocation. ${ }^{17}$ On 

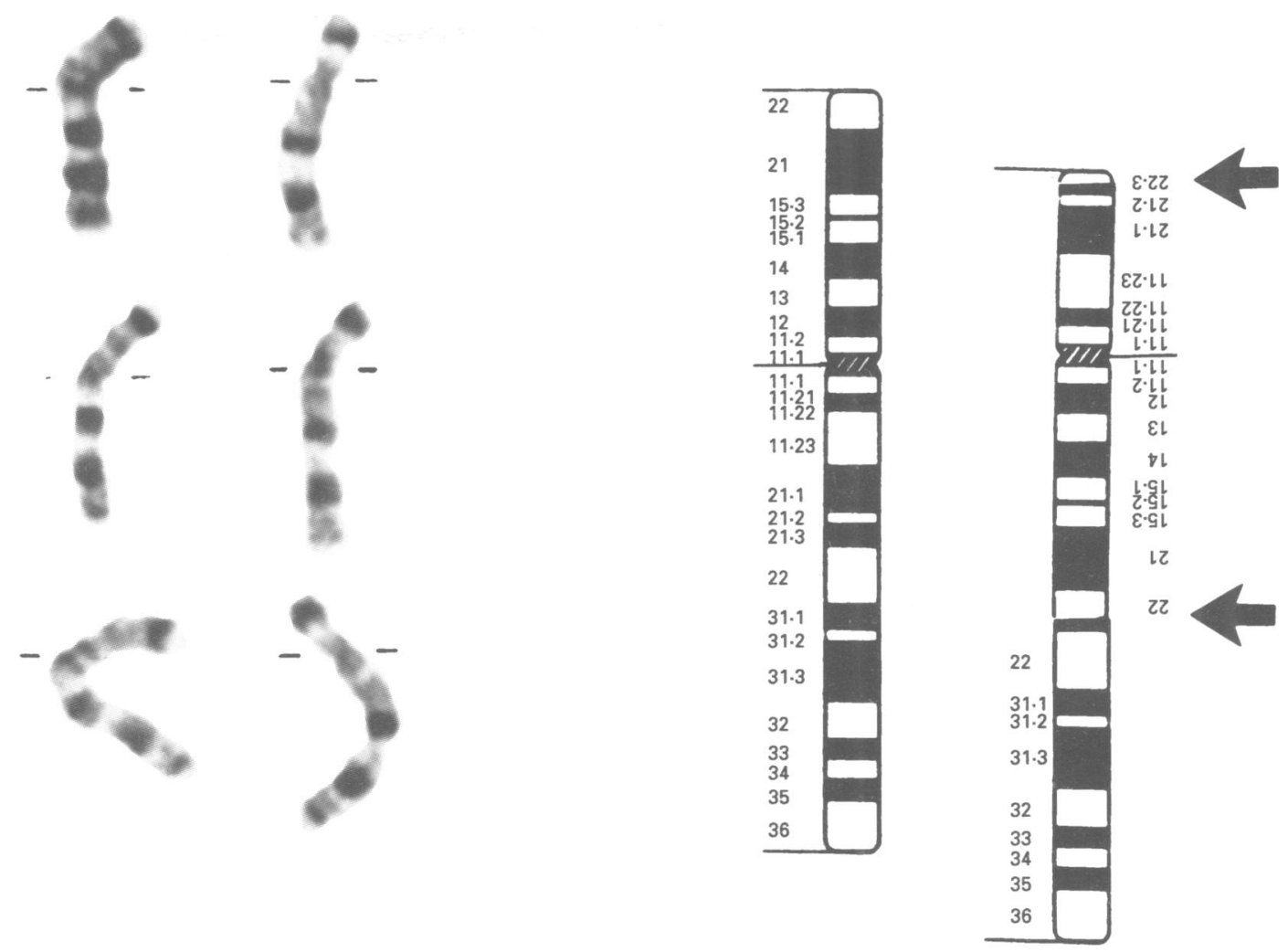

Figure 4 Partial karyotype of case 1 showing chromosomes 7 from three metaphases, the normal chromosome 7 on the left and the abnormal chromosome 7 on the right. The idiogram of chromosome 7 shows the inversion breakpoints in bands $7 p 22$ and $7 q 21.3$ (arrows).
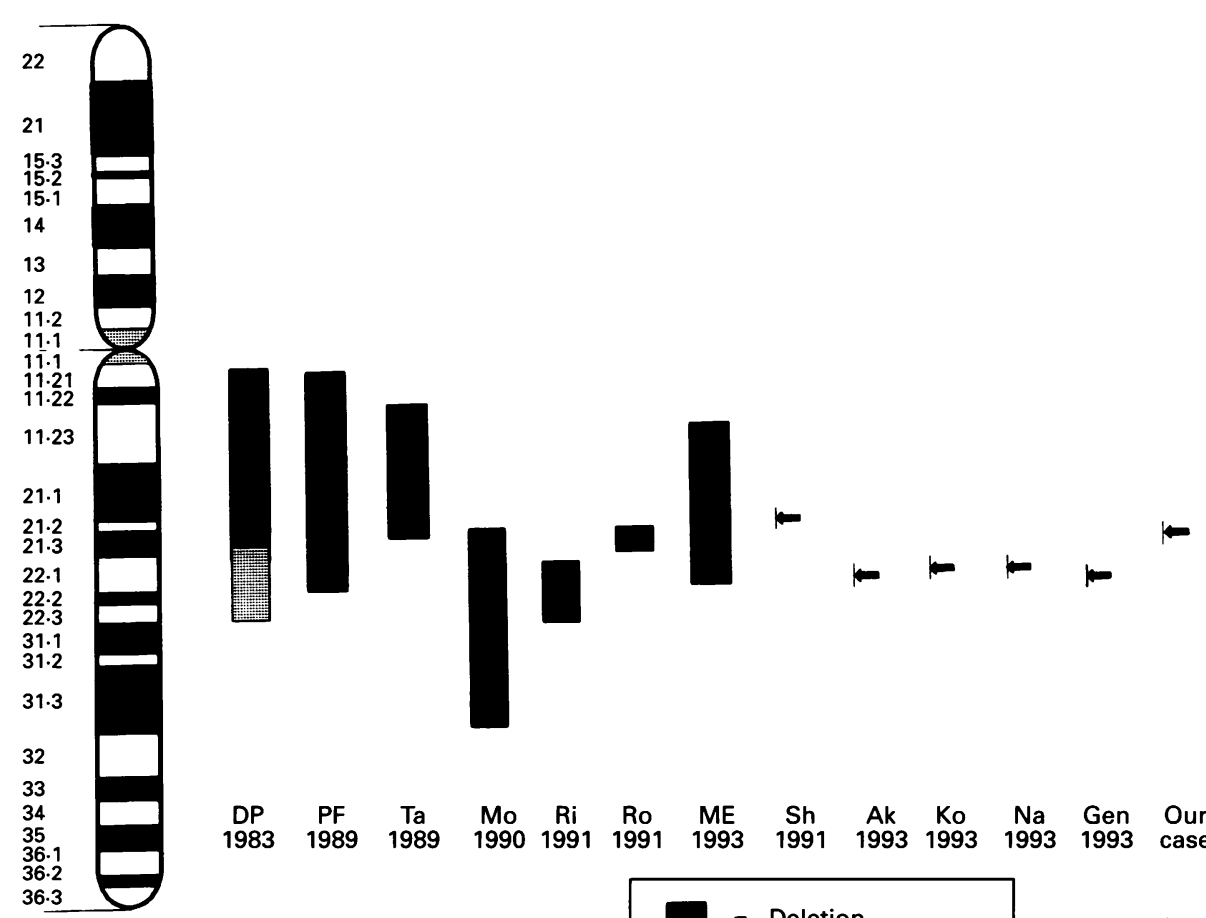

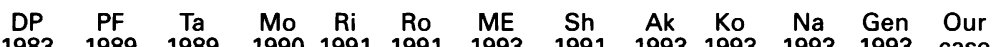

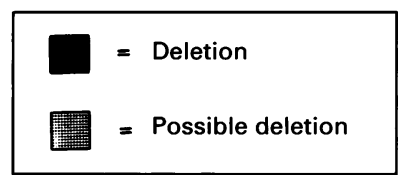

- Breakpoint structural aberration

Figure 5 Schematic drawing of the cytogenetic breakpoints in reported cases with split hand/foot malformation and an abberation in the chromosomal region $7 q$. Represented are 12 previously published cases (DP, Pf, Ta, Mo, Ri, Ro, ME, $\mathrm{Sh}, \mathrm{Ak}, \mathrm{Na}, \mathrm{Ko}, \mathrm{Ge}$ ) listed in the references, our case, and another published case (Ha) with a different breakpoint. For discussion see text. 
the other hand, it is also possible that this is an example of locus heterogeneity, as it was reported recently that not all cases of split hand/ foot anomalies are linked to chromosome $7 \mathrm{q} .{ }^{18}$

It appears that chromosome band $7 \mathrm{q} 21.3$ or the proximal region of band $7 \mathrm{q} 22$ or both are the most likely candidate regions for such a gene or genes. In our case, there is either a submicroscopic deletion of euchromatin in $7 \mathrm{q} 21.3$, or the breakpoint falls in the supposed split hand/foot gene itself, leading to an abnormal gene product.

It is somewhat puzzling, however, that ectrodactyly has been associated not only with balanced structural abnormalities involving breakpoints at 7q21-22, but also with deletions apparently involving these bands (fig 5). In fact, the former mechanism would still be compatible with partial disruption of the gene, whereas the latter implies loss of the locus where this disorder is supposedly located. Dominantly inherited gene disorders are usually the result of point mutations or partial deletions leading to abnormal gene products, rather than to complete deletion/inactivation of one allele. Therefore, it is possible that other genetic mechanisms, such as parental imprinting, might also be involved in the pathogenesis of this malformation. ${ }^{19}$ Parental imprinting does not seem to be likely in view of a recently published family with split hand/foot anomaly and a balanced translocation involving $7 \mathrm{q} 22.1,{ }^{11}$ giving no indication of genomic imprinting. The determination of the parental origin of the rearranged chromosomes 7 associated with ectrodactyly may shed light on possible (patho)genetic mechanisms involved in split hand/foot malformation.

Dominant split hand/foot is heterogeneous and has known variable expression and reduced penetrance. Elucidation of the genetic or epigenetic mechanisms responsible for these phenomena will be aided by the identification of the causative gene(s), and rare cases like ours may help in the gene localisation.
The authors thank Mrs Mentje Dijkstra for secretarial assistance.

1 Del Porto G, D’Allessandro E, De Matteis C, Lo Re ML Ivaldi $M$, Di Fusco $C$. Delezione interstiziale del braccio ungo del chromosoma 7 e sue correlazioni cliniche. lungo del chromosoma 7
Pathologica $1983 ; 75: 268-71$.

2 Pfeiffer RA. Interstitial deletion of a chromosome 7 (q11.q22.1) in a child with splithand/splitfoot mal Ann Genet (Paris) 1984;27:45-8.

3 Tajara EH, Varella-Garcia M, Gusson ACT. Interstitial long-arm deletion of chromosome 7 and ectrodactyly. Am ₹ Med Genet 1989;32:192-4.

4 Morey MA, Higgins RR. Ectro-amelia syndrome associated with an interstitial deletion of 7q. Am F Med Genet 1990; 35:95-9.

5 Roberts SH, Hughes HE, Davies SJ, Meredith AL. Bilateral split hand and split foot malformation in a boy with a de novo interstitial deletion of 7q21.3. F Med Genet 1991;28: 479-81.

6 Rivera H, Sanchez-Corona J, Burgos-Fuentes VR, Melendez-Ruiz MJ. Deletion of 7q22 and ectrodactyly. Genet Couns 1991;2:27-31.

7 Sharland M, Patton MA, Hill L. Ectrodactyly of hands and feet in a child with a complex translocation including 7q21.2. Am F Med Genet 1991;39:413-14.

8 Akita S, Kuratomi H, Abe K, Harada N, Mukae N, Niikawa N. EC syndrome in a girl with paracentric inversion (7) (q22.1;q36.3). Clin Dysmorphol 1993;2:62-7.

9 Koiffmann C, Waintal A, de Souza DH, Gonzales $\mathrm{CH}$, Coates MV. Human situs determination and chromosome constitution 46, XY,ins $(7 ; 8)$ (q22; $12 \mathrm{q} 24)$. Am $f$ Med Genet 1993;47:568-9.

10 Naritomi K, Izumikawa Y, Tohma T, Hirayama K. Inverted insertion of chromosome $7 \mathrm{q}$ and ectrodactyly. Am $\mathcal{J}$ Med insertion of chromos

11 Genuardi M, Pomponi MG, Sammito V, Bellussi A, Zollino M, Neri G. Split hand/split foot anomaly in a family segregating a balanced translocation with breakpoint on 7q22.1. Am f Med Genet 1993;47:823-31.

12. McElveen CL, Carvajal MV, Mascatello D, Towner J, Lacassie Y. Ectrodactyly and proximal/intermediate interstitial deletion 7q: a recognizable syndrome? Am f Hum Genet 1993;53:(suppl):473A.

13 Hasegawa T, Hasegawa Y, Asamura S, et al. EEC syndrome (ectrodactyly, ectodermal dysplasia and cleft lip/palate) with a balanced reciprocal translocation between $7 \mathrm{q} 11.2$ and $9 p_{12}$ (or $7 p_{11.2}$ and $9 \mathrm{q} 12$ ) in three generations. Clin Genet 1991;40:202-6.

14 Hall B. Vascular abnormality at the site of limb deficiency. Am F Med Genet 1992;43:619-20.

15 McKusick VA. Mendelian inheritance in man. 11 th ed. Baltimore: The Johns Hopkins University Press, 1994:1381

16 Qumsiyek MB. EEC syndrome (electrodactyly, ectodermal dysplasia and cleft lip/palate) is on $7 \mathrm{p} 11.2-\mathrm{q} 21.3$. Clin Genet 1992;42:101.

17 Wolff DJ, Schwartz S. The effect of Robertsonian translocation on recombination on chromosome 21. Hum Mole Genet 1993;2:693-9.

18 Gurrier F, Genuardi M, Chiurazzi P, Gillessen-Kaesbach G, Neri G. Exclusion of linkage between autosomal dominant Neri G. Exclusion of linkage between autosomal dominan split hand/split foot and markers from chromosome 7q: Genet 1994;55:853-5.

19 Jarvik GP, Patton MA, Homfray T, Evans JP. Non-Mendelian transmission in a human developmental disorder: split hand/split foot. Am $\mathcal{f}$ Hum Genet 1994;55:710-13. 